\title{
Embracing Uncertainty as a Path to Competence: Cultural Safety, Empathy, and Alterity in Clinical Training
}

\author{
Laurence J. Kirmayer
}

Published online: 29 March 2013

(C) Springer Science+Business Media New York 2013

\section{Introduction}

Models of cultural competence training in psychiatry reflect particular contexts of practice. These contexts map the boundaries of professional expertise and identify the kinds of social differences that are framed as 'cultural' and that warrant explicit attention in health care. Understanding the social-historical and political-economic contexts of training programs and health care systems is essential to appreciate their explicit goals and structure as well as their implicit assumptions and blind spots. In this commentary, I provide some context to the paper by Cécile Rousseau and Jaswant Guzder on their Working with Culture seminar at McGill University. I outline some of the distinctive pedagogical values and orientations in their approach and consider the implications of their work for research, training, and clinical practice.

\section{Multiculturalism and Social Constructions of the Other}

The workshop led by Rousseau and Guzder is part of the annual McGill Summer Program in Social and Cultural Psychiatry. Since 1994, we have run this international program to provide a venue for the intensive study of cultural issues in mental health (Kirmayer et al. 2008). The clinical workshop led by Drs. Guzder and Rousseau focuses on basic questions in the orientation of clinical work and especially on the clinicians' use of self. A companion course in cultural psychiatry reviews theory and research relevant to understanding the impact of culture and context on psychopathology, healing and mental health services. Other workshops

\footnotetext{
L. J. Kirmayer ( $₫)$

Division of Social and Transcultural Psychiatry, McGill University, 1033 Pine Avenue West, Montreal, QC H3A 1A1, Canada e-mail: laurence.kirmayer@mcgill.ca
} 
during the summer program address qualitative research methods, social psychiatry and psychiatric epidemiology, critical neuroscience, and global mental health (www.mcgill.ca/tcpsych/training/summer).

McGill is an English-language institution located in Montreal, a cosmopolitan, highly diverse city in Quebec, a predominately French-speaking province. Quebec is politically committed to preserving and promoting French language and Québecois identity. In accounts of Canadian history, the English and French settlers usually have been portrayed as the two founding peoples-ignoring the primacy of indigenous peoples (Bibeau 1998; Saul 2008). In Quebec, this coexistence gave rise to a 'distinct society' in which newcomers today are described in terms of their linguistic background as Anglophone, Francophone, and 'Allophone'. Recent years have seen a challenging public discussion about the limits of tolerance and "reasonable accommodation" to the other in society (Bouchard and Taylor 2008). Prompted by current global security concerns, these local debates engaged a broad segment of the public. Newcomers - whether immigrants or refugees-as well as established ethnocultural communities are viewed as being ethnically "other" in contrast to the dominant French Québecois group which, ironically, tends not see itself as ethnic.

The larger Canadian context also differs from that of the U.S. in important ways. Like the U.S., Canada is a nation of immigrants but while the U.S. adopted an explicit ideology of assimilation expressed in the metaphor of the 'melting pot' (Gilman 2006), Canada has been described as 'the vertical mosaic' or 'the house of difference' (Mackey 1999). The political framework of multiculturalism acknowledges this diversity and encourages groups to retain their sense of cultural distinctness and community (Kamboureli 1998). Despite recent criticism by conservative politicians and media, multiculturalism remains a key aspect of collective identity in Canada (Ryan 2010).

While much work on culture in mental health services in the U.S. has been framed in terms of the large ethnoracial blocs created by the imposition of census categories, this configuration of identity not been popular in Canada, where what might be called 'hyperdiversity' (cf. Hannah 2011; Good et al. 2011) has long prevailed. For the last 100 years, $15-20 \%$ of the population at any time was born outside the country. Given the long history and continuing importance of new migration, there is no sharp distinction between newcomers and ethnocultural communities. In a sense, everyone is a hyphenated Canadian, with distinctive and often mixed ethnocultural roots, making culture a salient issue in everyday life. Moreover, recent recognition of the historical injustices of the state-supported oppression and forced assimilation of Aboriginal peoples have led to a new level of attention to culture as a human right (Niezen 2009). Aboriginal peoples in Canada speak explicitly of the restoration of culture as the cure for the social suffering that has come from these destructive policies. The Mental Health Commission of Canada (2012) has endorsed the importance of "cultural safety" in mental health services, an approach derived from the work of Maori nurses in New Zealand, which emphasizes addressing issues of power, voice, and discrimination as an essential complement to professionals' cultural competence (Brascoupé and Waters 2009). 


\section{Distinctive Features of the 'Working with Culture' Seminar}

The workshop developed by Drs. Guzder and Rousseau has distinctive premises and pedagogical approaches. The central teaching material involves case studies situated within a bio-psychosocial model that integrates intra-psychic, systemic, historical, and socio-political dimensions. Clinical presentations are used to illustrate assessment ("knowing"), intervention ("know-how") and culturally meaningful outcome but also to stimulate discussion of the "not known". The unknown is emphasized by focusing on the inherent complexity of intercultural clinical encounters. The person of the clinician and the clinician-patient relationship is central to all of this work. Psychotherapy (including family therapy and other forms of intervention that use relationships to promote change) provides examples of processes that are at play even in brief clinical encounters.

Guzder and Rousseau describe four central tensions that organize their workshop and that mirror their approach to the clinical encounter:

(1) The tension between the comfort and safety of the familiar and the challenge of 'holding' difference and alterity. In the process of the workshop, the leaders work to create psychological and cultural safety. Through their own ways of being present and using self-disclosure, they serve as role models. The social space of Quebec itself stands for these same tensions. Indeed, Quebec has a long history of containing radical oppositions and tensions (Bibeau 1998), and this coexistence and dialogical process is vividly represented by the interaction of the co-leaders who are Anglophone and Francophone. This representational process also has distinctive gendered and political dimensions in that the leaders are both women who, while academically and professionally accomplished and established, are also iconoclastic in important waysknown for their spirited rejection of 'political correctness' and willingness to confront social injustice through advocacy. The political correctness they challenge is intrinsic to psychiatry as a conservative profession but it is also a feature of the larger society, which makes it hard to talk about certain topics. For example, liberal political perspectives in Canada often adopt a sort of colorblindness in the name of equality, making it difficult to discuss issues of racism and discrimination. By confronting these issues head on, the workshop leaders and their guest faculty work to expand the bounds of professional discourse.

(2) Challenging the expert position by engaging with interdisciplinarity and nonprofessional voices and perspectives. Professionals are taught to demonstrate their expertise by always having an authoritative answer ready to hand. In medical education, this position as expert is reinforced by the experience of certain popular styles of clinical teaching like the so-called 'Socratic method' in which a senior physician poses questions for which he or she already has a specific answer in mind. Students are rewarded not for original thinking or problem solving but for their capacity to guess the teacher's intention. In practice, this stance of being the knowing expert stifles dialogue and reinforces conventional thinking by conveying that there is one correct answer. In reality, 
multiple disciplinary perspectives are needed to understand the cultural contexts of illness experience (Dinh et al. 2012). Circumscribing the authority of psychiatry and opening up the discussion to multiple points of view within the classroom leaves more space for exploration, dialogue and deepening of a reflective process in learning and, by extension, clinical practice.

(3) Searching for meaning in the face of uncertainty by balancing clinical perspectives with the voice of the Other. The Working with Culture seminar recognizes uncertainty as a pervasive aspect of all clinical work that is especially relevant to the fragile position of the clinician as outsider or stranger in intercultural work (Kai et al. 2007). The seminar emphasizes the indeterminacy and polyvalence of meaning in clinical work: "clinical narrative is not a straightforward truth-seeking enterprise" but involves political issues of representation and positioning that inevitably work simultaneously to give voice and to compel silence, to empower and to marginalize certain subject positions. The deepest roots of the search for shared meaning in clinical work stem from the inescapable alterity of the encounter with the other. The philosopher Emmanuel Levinas (1998) has argued that the "face" of the other, their presence, vulnerability and ultimate unknowability, challenges us with a fundamental responsibility for hospitality, care, and a never-ending effort to understand through dialogue. This ethical stance toward the other manifests clinically in what Orange (2011) has called a hermeneutics of trust, in marked contrast to the hermeneutics of suspicion that characterized older psychodynamic approaches that often displace the voice of the other with the privileged knowledge of the analyst.

(4) Recognizing the voice of the collective within the individual. The focus of the seminar is on configurations of identity that reflect cultural inscapes-internal psychic reflections of social imaginaries. These reflect the ways we are all (intentionally or unwittingly) vehicles for collective identities, carrying these identities into the arena of the health care system and playing out versions of larger political conflicts in the microcosm of the clinical encounter. "Eliciting a multiplicity of voices and perceptions whether intra-psychic, systemic, socio-political, professional, mythic or historical, is central to this seminar experience." The diverse perspectives of seminar participants with different personal and professional backgrounds mirrors the challenge of diversity in clinical work. Recognition of this multiplicity in the seminar models a pluralistic clinical space. The group process enacts this pluralism and reveals its essential requirements: self-reflection, toleration, hospitality, respect for and serious engagement with the other.

\section{Implications for Research, Training, and Practice}

Although anthropologists have criticized the utility of the notion of culture in recent years, noting the ways in which it leads to reification and stereotyping when applied to clinical thinking, the term 'culture' remains a useful placeholder for many 
important dimensions of social life and experience, notably, the collective strengths, communal practices, and modes of identity, experience and communication that provide patients and clinicians with some of their deepest understandings and strongest commitments.

The Working with Culture seminar is an example of how skillful educators can make use of clinical wisdom, self-knowledge, and respect for diversity to create a learning environment in which the medium is the message. The emphasis in the workshop is on developing an ethical stance and its corresponding ethos. The overarching values of this ethos include the recognition and valorization of difference or alterity and the tolerance, or active embrace, of uncertainty. Tolerance of uncertainty reflects the epistemic limits of clinical ways of knowledge but also serves an ethics of relatedness that allows the patient autonomy and room for selffashioning. This ethics of relation has therapeutic value as a counter to authoritarian voices that have silenced the self. It stands for ways of relating with the other that work to undo some of the violence of colonial relationships of domination and disparagement that persist in the contemporary world. The dilemmas for participants seeking to apply this ethos to their everyday practice lie in three areas: (i) the intolerance for uncertainty in professional settings; (ii) the extent to which the personal qualities of the seminar leaders are essential to their work as clinicians; and (iii) the challenge of maintaining appropriate authority and expertise in the service of patients and their families.

In an interesting way, Guzder and Rousseau work against the dominant metaphor of cultural competence as a form of expertise to emphasize the importance of clinicians' ability to acknowledge, tolerate and explore their own experiences of uncertainty, confusion, and limitations in intercultural clinical work. There are several kinds of uncertainty relevant to understanding the epistemic constraints of the clinical setting. These include uncertainty about the nature of clinical problems due to the limits of technical knowledge and of information available about the patient. The information available about the patients problem is limited in several ways: practically, by the depth and length of clinical investigation, which reflects structural and economic constraints in clinical settings; psychologically, by patients' unwillingness to divulge intimate or embarrassing information, their limited selfknowledge and emotional defensiveness; socially, by limits on the ability of both patient and clinician to understand and reflect on the institutional, social, and cultural contexts in which they are embedded; intersubjectively, by the limits of empathy which reflect difficulty in imagining patients situation or predicament, difficulty tolerating the intensity of patients' traumatic experiences, or the tendency to confuse the patient's experience with one's own (Kirmayer 2008).

Professions have ways to manage these forms of uncertainty because they represent threats to professional authority and expertise-although the only indeterminacy that is widely acknowledged in medicine is that attributed to the limits of technical knowledge and the vagaries of patients who are "unreliable historians." Psychodynamic psychiatry adds awareness of the motivated blockages and distortions of self-knowledge of patient and clinician (transference and countertransference) and there has been some discussion of the wider cultural ramifications of this in terms of cultural transference and counter-transference. But it is medical 
sociology and anthropology that have drawn attention to the central importance of the management of uncertainty in the institutions of medicine. There is a literature in medical sociology addressing the dilemmas of uncertainty in medicine (Fox 1957; Light 1980). This focuses on the ways in which professional training and interaction work to contain the destabilizing effects of uncertainty, shoring up authority and maintaining the power of medical experts. For many years, psychodynamic reasoning served to provide explanations that trumped patients' own self-understanding. This hermeneutics of suspicion gave clinicians rhetorical authority and protected them from the evident limitations of available interventions. In the clinical setting, these maneuvers may result in silencing patients and blaming them for the limitations of medical knowledge and treatment.

The reader of their paper may not fully appreciate the unique qualities of Drs. Guzder and Rousseau - and of the colleagues they invite to join them-as teachers, practitioners, and individuals who exemplify a respectful, nurturing, tolerant, open stance that goes far to create a "holding environment" where participants are safe to explore their own emotional reactions, personal commitments, and institutional predicaments. To judge from conversations with students and their written evaluations of the workshop, it is this personal embodiment and expression of the values of open community, dialogue and self-reflexivity-more than any formal principles of 'cultural safety' - that makes the workshop experience so positive for participants. However, cultural safety is a useful rubric to organize this ethos, and guide its transfer from the teaching setting to the organization of health services (Kirmayer 2012). In the pedagogical setting, the notion of cultural safety amounts to several key strategies: recognizing the histories and current contexts that structure inequality; embodying and enacting difference, mutual respect, and serious but playful engagement; and especially, an explicit emphasis on tolerance of notknowing as a bracketing of professional expertise, a realistic appraisal of limitations, and an ethical stance before the face of the other.

Balancing this reflective stance is a strong commitment to advocacy-justified in part by the authors' rejection of what they call "the delusion of neutrality." In using such critical language to dismiss the claims of 'neutrality', they mean to highlight the sense in which, given what is a stake in any clinical encounter, the clinician has no choice but to take a stand-indeed, the attempt to display neutrality at times can be the most biased and provocative stance imaginable. In their community work, Guzder, Rousseau, and their colleagues argue for a broader role for clinicians not simply as medical experts but as advocates and partners with patients and community systems.

While the Working with Culture seminar presents many strategies for institutional change, the emphasis throughout is on core values and attitudes. Conveying these overarching values and attitudes may have more impact than approaches that focus on specific clinical techniques or knowledge of local ethnocultural groups. This encourages the clinician to think in terms of their own cultural being. Ultimately, it is by seeing oneself as an other that the clinician can achieve greater empathy and understanding.

Evaluations of the workshop by participants have been consistently positive, with many describing it as having a profound effect on their clinical orientation and 
aspirations. Whether this translates into new ways of doing clinical work remains unclear-except in the case of participants from our own region, where we can confirm that it has contributed to creating a community of practice that supports culturally informed and politically aware clinicians.

\section{References}

Bibeau, Gilles

1998 Tropismes Québecois. Je me souviens dans l'oubli. Anthropologie et Sociétés 19(3): 151-198.

Bouchard, Gerard, and Charles B Taylor

2008 Building the Future: A Time for Reconciliation. Quebec: Government of Quebec.

Brascoupé, Simon, and Catherine Waters

2009 Cultural Safety: Exploring the Applicability of the Concept of Cultural Safety to Aboriginal Health and Community Wellness. Journal of Aboriginal Health 7(1): 6-40.

Dinh, Nathalie M.-H., et al.

2012 Influence of the DSM-IV Outline for Cultural Formulation on Multidisciplinary Case Conferences in Mental Health. Anthropology \& Medicine 19(2): 261-276.

Fox, Renée

1957 Training for uncertainty. In The Student Physician. RK Merton, G Reader, and P Kendall, eds. Cambridge, MA: Harvard University Press.

Gilman, Sander L

2006 Multiculturalism and the Jews. New York: Routledge.

Good, Mary-Jo D, SS Willen, SD Hannah, K Vickery, and LT Park, eds.

2011 Shattering Culture: American Medicine Responds to Cultural Diversity. New York: Russell Sage Foundation.

Hannah, Seth

2011 Clinical Care in Environments of Hyperdiversity. In Shattering Culture: American Medicine Responds to Cultural Diversity. MJD Good, SS Willen, SD Hannah, K Vickery, and L Park, eds. New York: Russell Sage Foundation.

Kai, J, et al.

2007 Professional uncertainty and disempowerment responding to ethnic diversity in health care: a qualitative study. PLoS Medicine 4(11): e323.

Kamboureli, Smaro

1998 The Technology of Ethnicity: Canadian Multiculturalism and the Language of Law. In Multicultural States: Rethinking Difference and Identity. D Bennett, ed., pp. 208-222. London: Routledge.

Kirmayer, Laurence J

2008 Empathy and Alterity in Cultural Psychiatry. Ethos 36(4): 457-474.

2012 Rethinking Cultural Competence. Transcultural Psychiatry 49(2): 149-164.

Kirmayer, Laurence J, Cécile Rousseau, Jaswant Guzder, and G. Eric Jarvis

2008 Training Clinicians in Cultural Psychiatry: A Canadian Perspective. Academic Psychiatry 32(4): 313-319.

Levinas, Emmanuel

1998 Entre Nous: Thinking of the Other. New York: Columbia University Press.

Light, Donald

1980 Becoming Psychiatrists: The Professional Transformation of Self. New York: Norton.

Mackey, Eva

1999 The House of Difference: Cultural Politics and National Identity in Canada. New York: Routledge.

Mental Health Commission of Canada

2012 Changing Directions, Changing Lives: The Mental Health Strategy for Canada. Ottawa: Mental Health Commission of Canada.

Niezen, Ronald

2009 The Rediscovered Self: Indigenous Identity and Cultural Justice. Montreal: McGill-Queen's Press. 
Orange, Donna M

2011 The Suffering Stranger: Hermeneutics for Everyday Clinical Practice. New York: Routledge/ Taylor \& Francis Group.

Ryan, Phil

2010 Multicultiphobia. Toronto: University of Toronto Press.

Saul, John Ralston

2008 A Fair Country: Telling Truths About Canada. Toronto: Viking Canada. 